\title{
Knowledge, attitudes, and perceptions of antenatal women to postpartum bilateral tubal ligation at Greys Hospital, KwaZulu-Natal, South Africa
}

\author{
Bongumusa Steven Makhathini ${ }^{1}$, Polycarpe N'djugumu Makinga ${ }^{2}$, Randolph Robert Green-Thompson ${ }^{3}$
}

1. Department of Obstetrics and Gynecology, Greys Hospital, Pietermaritzburg, and Nelson R. Mandela School of Medicine, College of Health Sciences, University of KwaZulu-Natal, Durban,, South Africa.

2. Department of Family Medicine, Ladysmith Hospital, Ladysmith and University Of KwaZulu-Natal, Durban, South Africa.

3. Department of Obstetrics and Gynecology, King Edward VIII, and Nelson R. Mandela School of Medicine, College of Health Sciences, University of KwaZulu-Natal, Durban, South Africa.

\begin{abstract}
:
Objectives: To evaluate the associations between socio-demographic factors and the general knowledge, the attitudes and perceptions of women attending antenatal clinic at Greys Hospital regarding postpartum tubal ligation (BTL).

Methods: A prospective cross-sectional study describing the perceptions about BTL in 241 pregnant women was conducted.

Results: One hundred and sixty six (68.9\%) participants needed to involve their partners before tubal ligation. Thirty five percent of 102 participants who would not have BTL against partner's wish were unemployed. Eighty three (34.4\%) participants, mostly with secondary and tertiary education believed that successful reversal of BTL is guaranteed. Fifty two percent of participants, predominantly with no formal schooling and primary education levels were unaware of the risk of falling pregnant after BTL. Sixty seven $(27.8 \%)$ participants, predominantly with primary education or no formal schooling believed that BTL protects against STIs and HIV. Seventy eight (32.4\%) of participants would not have BTL due to religious beliefs, however, participants from the same religion gave different answers to the question.

Conclusion: The study showed a significant lack of knowledge on key points of BTL. Socio-demographic factors still influence this subject and should not be underestimated during counselling of the patients to reduce potential morbidity and litigation.
\end{abstract}

Keywords: Knowledge, attitudes, perceptions, antenatal women, tubal ligation.

DOI: https://dx.doi.org/10.4314/ahs.v19i3.37

Cite as: Makhathini BS, Makinga PN, Green-Thompson RR. Knowledge, attitudes, and perceptions of antenatal women to postpartum bilateral tubal ligation at Greys Hospital, KwaZulu-Natal, South Africa. Afri Health Sci. 2019;19(3): 2615-2622. bttps:/ / dx.doi.org/10.4314/ahs.v19i3.37

\section{Introduction}

Low income countries, globally have a significant $26 \%$ of unmet need for modern family planning methods. Some $18 \%$ of women who want to avoid pregnancy are not using any contraception. The proportion of women with unmet needs for modern methods is $53 \%$ in Africa and $17 \%$ in the Southern African region. ${ }^{1}$ This is concerning

\section{Corresponding author:}

Bongumusa Steven Makhathini,

Greys Hospital Private Bag x9001

Pietermaritzburg South Africa 3200

Fax 0866474230

Telephone numbers: (033) 8973292

Mobile phone: +270723933751

Email: musamakh@yahoo.com because unplanned pregnancies have a significant negative impact on the health, social and economic systems of the countries. Effective and reliable contraception is important in prevention of unplanned pregnancies. Bilateral tubal ligation (BTL) is one of the most reliable forms of contraception, with a low failure rate of $0.5 \%$ in the first twelve months and $1.85 \%$ at 10 years of cumulative use. ${ }^{2-3}$

The postpartum period is a convenient and cost effective time to perform BTL. This can be done during the caesarean section $(\mathrm{C} / \mathrm{S})$ or as a sub-umbilical mini-laparotomy post vaginal delivery (VD) before uterine involution. It is common to find women with pregnancy-related high risk factors like advanced maternal age or other life threatening co-morbidities declining this method. On the other hand some young and low risk patients would opt for BT over reversible contraceptive methods. This could 
be due to lack of correct information and misperceptions regarding BTL. The antenatal period is crucial in counselling patients about contraception, especially with regards to postpartum BTL. Effective counselling empowers patients to make an informed decision and to avoid improperly consenting to BTL.

Barriers to BTL include poor antenatal care. Some patients from low income settings do not attend nor have access to antenatal care facilities, book late and present when in labour. This affects proper counselling to impact knowledge and eliminate myths and misconception about BTL. It also affects the timing of taking consent for BTL. Shortage of resources such as theatre room availability, theatre time and theatre staff, contribute to the unmet need for post VD patients requesting BTL. Different sectors of the government, non-governmental organizations, the community and health care workers are the prominent enablers for BTL. Health care workers looking after pregnant women must advocate for the urgency of the procedure for post VD patients who request BTL. The aim of this study was to explore the associations between the socio-demographic factors (area of residence, education, religion and employment) and the general knowledge, attitudes and perceptions of women attending high risk clinic of Greys Hospital towards postpartum BTL. The researchers did not come across any published similar study which was conducted in Pietermaritzburg or in the province of KwaZulu-Natal. This makes the study to be the first of its kind to explore the knowledge, attitudes and perceptions of antenatal women to tubal ligation in the area.

\section{Methods}

This was a prospective cross-sectional study. Following ethical approval by the University of KwaZulu-Natal Biomedical Research Ethics Committee (REF: BE 314/12), permission to conduct the study was obtained from Grey's Hospital management. Greys Hospital is a tertiary institution situated in Pietermaritzburg, KwaZulu-Natal province of South Africa. It offers high risk obstetric services to patients referred by district and regional hospitals of the surrounding rural, suburban and township communities of area 2 of KwaZulu-Natal Province. Due to shortage of regional hospitals in this area, some district hospitals refer directly to Grey's Tertiary Hospital to improve service delivery. For the purpose of this study, the rural area refers to the area of residence with none to minimal basic infrastructure, away from the city and commonly used by poor and low income class communities. Township refers to the area of residence with minimum to average basic infrastructure, commonly used by a combination of low and middle income communities. Suburban refers to areas of residence with efficient basic and social infrastructure, in between the cities and townships, and commonly used by middle and upper communities.

The questionnaire was formulated in English and isiZulu languages and focused on demographic variables which were thought to be influential to the topic as well as specific questions related to tubal ligation to test participants' background knowledge. Participants' identification data such as their name and surname were omitted to ensure confidentiality. The study was conducted from the $1^{\text {st }}$ of April 2013 to the $31^{\text {st }}$ of October 2013 using systematic random sampling on days convenient to the principal investigator. Both first time and repeat visit patients were recruited for the study. A written consent was obtained from the agreeable study participants. Questions were explained to the participants and they filled in the forms individually. Completed questionnaires were collected by the clinic staff involved in the study and handed over to the principal researcher to be locked safely.

Descriptive statistics were computed using SPSS version 21. Kolmogorov-Smirnov test was used to test the distribution of the data. Chi-square test of association was used for non-parametric distribution of data and a $\mathrm{p}$ value $<0.05$ was considered statistically significant. The reliability coefficient used in this survey was the Cronbach's alpha to assess how consistent and generalizable the results were, if we increased the sample size.

\section{Results}

Two hundred fifty six women participated in the study. Fifteen questionnaires were partially filled in with insufficient information for the objectives of the study, therefore excluded from the study. Two hundred and forty one questionnaires were analysed. Of the 241 study participants $55(22.8 \%)$ were aged $\leq 25$ years, $150(62.2 \%)$ were aged 26 to 40 years and $36(14.9 \%)$ were aged $\geq 41$ years. Two hundred and five (85.1\%) participants were Black Africans, followed by $21(8.7 \%), 11(4.6 \%)$ and $4(1.7 \%)$ of Indian, Coloured and White race participants respectively. Christian and Nazareth/Shembe religions were the most represented in the sample by $170(70.5 \%)$ and 37 
(15.4\%) respectively. Most patients came from the rural areas $112(46.5 \%)$ while 66(27.4\%) and 63(26.1\%) came from township and suburban areas respectively. The level of education of the participants can be summarized as $12.0 \%, 18.7 \%, 16.2 \%$ and $53.1 \%$ for "never" went to school, primary, secondary and tertiary education re- spectively. One hundred and eighty six $(77.1 \%)$ were unemployed compared to $55(22.9 \%)$ who had a job. One hundred and fifty seven $(65.1 \%)$ participants were not married compared to $84(34.9 \%)$ who were married.

The socio-demographic characteristics of the participants based on their area of residence are summarised in Table 1.

Table 1: Socio-demographic characteristics based on areas of residence

\begin{tabular}{|c|c|c|c|c|}
\hline $\begin{array}{c}\text { Socio-demographic } \\
\text { Variable }\end{array}$ & $\begin{array}{c}\text { Rural } \\
(\mathrm{N}=112) \\
\mathrm{n}(\%)^{*}\end{array}$ & $\begin{array}{c}\text { Township } \\
(\mathrm{N}=66) \\
\mathrm{n}(\%)^{*}\end{array}$ & $\begin{array}{c}\text { Suburban } \\
(\mathrm{N}=63) \\
\mathrm{n}(\%)^{*}\end{array}$ & $\begin{array}{c}\text { Total }(N=241) \\
n(\%)^{*}\end{array}$ \\
\hline \multicolumn{5}{|l|}{ Age in years } \\
\hline$\leq 25$ & $18(7.5)$ & $20(8.3)$ & $17(7.1)$ & $55(22.8)$ \\
\hline $26-30$ & $17(7.1)$ & $14(5.8)$ & $25(10.4)$ & $56(23.2)$ \\
\hline $31-35$ & $32(13.3)$ & $17(7.1)$ & $8(3.3)$ & $57(23.7)$ \\
\hline $36-40$ & $21(8.7)$ & $6(2.5)$ & $10(4.1)$ & $37(15.4)$ \\
\hline$\geq 41$ & $24(10.0)$ & $9(3.7)$ & $3(1.2)$ & $36(14.9)$ \\
\hline \multicolumn{5}{|l|}{ Religion } \\
\hline Christian & $70(29,0)$ & $55(22.8)$ & 45 (18.7) & $170(70.5)$ \\
\hline Muslim & $1(0.4)$ & $0(0.0)$ & $4(1.7)$ & $5(2.1)$ \\
\hline Nazareth/Shembe & $23(9.5)$ & $9(3.7)$ & $5(2.1)$ & $37(15.3)$ \\
\hline Hindu & $3(1.2)$ & $0(0.0)$ & $4(1.7)$ & $7(2.9)$ \\
\hline Other & $15(6.2)$ & $2(0.8)$ & $5(2.1)$ & $22(9.1)$ \\
\hline \multicolumn{5}{|l|}{ Education } \\
\hline Never went to school & $25(10.4)$ & $2(0.8)$ & $2(0.8)$ & $29(12.0)$ \\
\hline Grade $1-7$ & $26(10.8)$ & $13(5.4)$ & $6(2.5)$ & $45(18.7)$ \\
\hline Grade $8-12$ & $53(22.0)$ & $39(16.2)$ & $36(14.9)$ & $128(53.1)$ \\
\hline Tertiary & $8(3.3)$ & $12(5.0)$ & $19(7.9)$ & $39(16.2)$ \\
\hline \multicolumn{5}{|l|}{ Employment status } \\
\hline Employed & $21(8.8)$ & $16(6.7)$ & $18(7.5)$ & $55(23.0)$ \\
\hline Unemployed & $90(37.5)$ & $50(20.8)$ & $45(18.8)$ & $186(77.1)$ \\
\hline \multicolumn{5}{|l|}{ Marital status } \\
\hline Single & $85(35.3)$ & $43(17.8)$ & $29(12.0)$ & $157(65.1)$ \\
\hline Married & $27(11.2)$ & $23(9.5)$ & $34(14.1)$ & $84(34.8)$ \\
\hline
\end{tabular}

$*$ Percentage calculated on the denominator of $n=241$

Data related to parity was multimodal. While 74 participants (39.4\%) reported to have one child, 32 participants
$(17.0 \%)$ reported to have four or more live children. Information about previous mode of delivery is summarized in Table 2. 
Table 2: Obstetric variables

\begin{tabular}{|l|r|r|}
\hline Variable & $\mathbf{n}$ & $\mathbf{2}$ \\
\hline Parity: & 53 & 22.0 \\
\hline 0 & 54 & 22.4 \\
\hline 1 & 43 & 17.8 \\
\hline 2 & 38 & 15.8 \\
\hline 3 & 53 & 22.0 \\
\hline$\geq 4$ & 15 & 8.0 \\
\hline Number of live children: & 74 & 39.4 \\
\hline 0 & 38 & 20.2 \\
\hline 1 & 29 & 15.4 \\
\hline 2 & 32 & 17.0 \\
\hline 3 & & \\
\hline$\geq 4$ & 136 & 56,4 \\
\hline Previous mode of delivery: & 52 & 21,6 \\
\hline Vaginal Delivery & \multicolumn{2}{|r|}{} \\
\hline Caesarean Section &
\end{tabular}

One hundred and thirty two (54.8\%) participants reported to have reached their desired family size, of which 15 $(6.6 \%)$ were $\leq 25$ years. There was a statistical significant association between the variables 'reaching desired family size' and 'parity' $\left(\chi^{2}=49.63 ; \mathrm{p}=0.00\right)$. Thirty one $(12.8 \%)$ of women $\geq 36$ years of age had more than four live babies. One hundred and sixty three (68.5\%) participants agreed to BTL once their desired family size was complete, of which $35(14.5 \%)$ were participants $\leq 25$ years and $60(24.9 \%)$ were $\geq 36$ years of age. However, $13(5.4 \%)$ participants $\geq 36$ years of age were not agree- able to BTL after completing their desired family size. Eighty three $(34.4 \%)$ participants believed that successful reversal of BTL is guaranteed should they desire future fertility; of which 25 (10.4\%) were $\leq 25$ years of age.

One hundred and sixty six $(68.9 \%)$ participants agreed that they needed to involve their spouses/partners in the decision of BTL and 102 (42.3\%) stated that they would not have BTL done if their partners were opposed to the decision. Further details of findings on knowledge, attitudes and perceptions of participants on BTL are summarised in Table 3. 
Table 3: Knowledge, attitude and perceptions of participants towards bilateral tubal ligation

\begin{tabular}{|c|c|c|}
\hline Knowledge, attitude and perceptions related questions & $\begin{array}{l}\text { Yes } \\
\mathbf{n}(\%)\end{array}$ & $\begin{array}{l}\text { No } \\
\text { n(\%) }\end{array}$ \\
\hline Have you reached your target number of babies? & $\begin{array}{r}132 \\
(54.8) \\
\end{array}$ & $\begin{array}{r}109 \\
(45.2) \\
\end{array}$ \\
\hline $\begin{array}{l}\text { Do you want a permanent contraception in the form of BTL } \\
\text { once your target is reached? }\end{array}$ & $\begin{array}{r}165 \\
(68.5) \\
\end{array}$ & $\begin{array}{r}76 \\
(31.5) \\
\end{array}$ \\
\hline Does your religion allow you to have BTL? & $\begin{array}{r}163 \\
(67.6) \\
\end{array}$ & $\begin{array}{r}78 \\
(32.4) \\
\end{array}$ \\
\hline Do you need to involve your spouse in the decision of BTL? & $\begin{array}{r}166 \\
(68.9) \\
\end{array}$ & $\begin{array}{r}75 \\
(31.1) \\
\end{array}$ \\
\hline Can you still have BTL even if your spouse is against your decision? & $\begin{array}{r}102 \\
(42.3)\end{array}$ & $\begin{array}{r}139 \\
(57.7)\end{array}$ \\
\hline Will BTL protect you from STIs/ HIV? & $67(27.8)$ & $\begin{array}{r}174 \\
(72.2) \\
\end{array}$ \\
\hline Is there a small risk of falling pregnant after BTL? & $\begin{array}{r}116 \\
(48.1) \\
\end{array}$ & $\begin{array}{r}125 \\
(51.9) \\
\end{array}$ \\
\hline Can pregnancy occur outside your womb? & $\begin{array}{r}105 \\
(43.6) \\
\end{array}$ & $\begin{array}{r}136 \\
(56.4) \\
\end{array}$ \\
\hline $\begin{array}{l}\text { Are you allowed to change your mind about BTL before the procedure is } \\
\text { done? }\end{array}$ & $\begin{array}{r}144 \\
(59.8)\end{array}$ & $\begin{array}{r}97 \\
(40.2)\end{array}$ \\
\hline Will BTL negatively affect your sexual life & $45(18.7)$ & $\begin{array}{r}196 \\
(81.3) \\
\end{array}$ \\
\hline Is BTL reversal guaranteed if you need to conceive & $83(34.4)$ & $\begin{array}{r}158 \\
(65.6) \\
\end{array}$ \\
\hline \multicolumn{3}{|l|}{ What is your contraceptive alternative if BTL is not desired? } \\
\hline Pills & $\begin{array}{r}49 \\
(20.3) \\
\end{array}$ & \\
\hline Injections & $\begin{array}{r}161 \\
(66.8) \\
\end{array}$ & \\
\hline Intrauterine contraceptive device & $\begin{array}{r}31 \\
(12.9)\end{array}$ & \\
\hline
\end{tabular}

BTL: bilateral tubal ligation; STIs: sexual transmitted infections; HIV: human immunodeficiency virus

The study found that $125(51.9 \%)$ participants were unaware of the risk of becoming pregnant after BTL. This was more evident in participants with no formal education where $21(8.7 \%)$ were unaware of this risk versus $8(3.3 \%)$ who were aware of a possible risk, which was statistically significant $(p=0.037)$. Sixty-seven $(27.8 \%)$ participants, believed that BTL protects against STIs/ HIV, which was statistically significant when cross tabulated to their level of education $(\mathrm{p}=0.001)$.

Ninety seven $(40.2 \%)$ women believed that they could not change their minds before the procedure is done. This finding was also statistically significant ( $p=0.001)$. When asked whether they believed that BTL will negatively affect their sex life, 45 women (18.8\%) said "Yes" and 196 $(81.2 \%)$ said "No". The Chi-squared test of association of the finding on this belief and the level of education revealed a statistically significant association $(p=0.004)$. The Chi-square test of association between the variable level of education and the belief that the reversal of BTL was guaranteed was statistically significant $(p=0.033)$. Further results of cross-tabulation between the variable 'level of education' and variables related to knowledge, attitude and perceptions on postpartum BTL are summarised in Table 4. 
Table 4: Impact of level of education to knowledge, attitudes and perceptions to post-partum BTL

\begin{tabular}{|c|c|c|c|c|c|}
\hline Variables & $\begin{array}{c}\text { Never went to school } \\
(\mathbf{N}=29) \\
\mathbf{n}(\%)^{+}\end{array}$ & $\begin{array}{c}\text { Grade 1- } \\
7 \\
(\mathbf{N}=45) \\
\mathbf{n}(\%) \\
\end{array}$ & $\begin{array}{c}\text { Grade 8- } \\
12 \% \\
(\mathbf{N}=128) \\
\mathbf{n}(\%) \\
\end{array}$ & $\begin{array}{c}\text { Tertiary Education } \\
(\mathbf{N}=39) \\
\mathbf{n}(\%)^{+} \\
\end{array}$ & $\underset{*}{\mathbf{p} \text { Value }}$ \\
\hline \multicolumn{5}{|c|}{ Can you still have BTL if your spouse is against your decision? } & \multirow[t]{3}{*}{0.176} \\
\hline Yes & $12(5.0)$ & $30(12.4)$ & $73(30.3)$ & $24(10.0)$ & \\
\hline No & $17(7.1)$ & $15(6.2)$ & $55(22.8)$ & $15(6.2)$ & \\
\hline \multicolumn{5}{|c|}{ Is there a small risk of falling pregnant after BTL? } & \multirow[t]{3}{*}{0.037} \\
\hline Yes & $8(3.3)$ & $19(7.9)$ & $71(29.5)$ & $18(7.5)$ & \\
\hline No & $21(8.7)$ & $26(10.8)$ & $57(23.7)$ & $21(8.7)$ & \\
\hline \multicolumn{5}{|c|}{ Will BTL protect you from STIs/ HIV? } & \multirow[t]{3}{*}{0.001} \\
\hline Yes & $11(4.6)$ & $24(9.9)$ & $28(11.6)$ & $6(2.5)$ & \\
\hline No & $18(7.5)$ & $23(9.5)$ & $100(41.5)$ & $33(13.7)$ & \\
\hline \multicolumn{5}{|c|}{ Can you change your mind about BTL before the procedure? } & \multirow[t]{3}{*}{0.001} \\
\hline Yes & $6(2.5)$ & $21(8.7)$ & $96(39.8)$ & $21(8.7)$ & \\
\hline No & $23(9.5)$ & $24(10.0)$ & $32(13.3)$ & $18(7.5)$ & \\
\hline \multicolumn{5}{|c|}{ Will BTL negatively affect your sexual life? } & \multirow[t]{3}{*}{0.004} \\
\hline Yes & $5(2.1)$ & $12(7.1)$ & $18(7.5)$ & $5(2.1)$ & \\
\hline No & $23(9.6)$ & $28(11.7)$ & $110(45.8)$ & $34(14.2)$ & \\
\hline \multicolumn{5}{|c|}{ Is reversal of BTL guaranteed if you need to conceive? } & \multirow[t]{3}{*}{0.033} \\
\hline Yes & $5(2.1)$ & $12(5.0)$ & $54(22.4)$ & $12(5.0)$ & \\
\hline No & $24(10.0)$ & $33(13.7)$ & $74(30.7)$ & $27(11.2)$ & \\
\hline \multicolumn{5}{|c|}{ What is your contraceptive alternative if BTL is not desired? } & \multirow[t]{4}{*}{0.506} \\
\hline Pills & $5(2.1)$ & $7(2.9)$ & $27(30.3)$ & $10(4.1)$ & \\
\hline Injections & $23(9.5)$ & $33(13.7)$ & $34(34.0)$ & $23(9.5)$ & \\
\hline IUCD & $1(0.4)$ & $5(2.1)$ & $19(7.9)$ & $6(2.5)$ & \\
\hline
\end{tabular}

There was no statistical significance on these variables analysed based on area of residence. However, the study found that $65(26.9 \%)$ participants from rural area, $31(12.9 \%)$ from township and 30(12.4\%) from suburban area had no knowledge of the possible risk of conceiving post BTL. Misperception that BTL would protect women against STIs (including HIV) was present in 33(13.7\%), $20(8.3 \%)$ and $14(5.8 \%)$ participants from rural, township and suburban areas respectively.

The study also showed that $139(57.7 \%)$ participants agreed that they could not have BTL if their spouses or partners were against their decision and 100(41.7\%) of those participants come from the unemployed sub-group of the sample. However, 85(35.4\%) of unemployed participants could have BTL irrespective of the spouse/ partners' decision. The cross tabulation on this point was statistically significant $(p=0.03)$.

The results showed that there were different religious opinions regarding postpartum BTL. The majority of Christians and Hindus thought that BTL was allowed in their religious faith. On the other hand, more Muslims and Nazareth / Shembe women responded that their religion did not allow BTL. 
Table 4: Bilateral tubal ligation and religion

\begin{tabular}{|c|c|c|c|}
\hline \multirow{2}{*}{ Religion } & \multicolumn{2}{|c|}{ My religion allows me to have BTL n (\%)* } & \multirow{2}{*}{$\begin{array}{c}\text { Total } \\
\text { N(\%)* }\end{array}$} \\
\cline { 2 - 3 } & Yes & No & $170(70.5)$ \\
\hline Christian & $129(53.5)$ & $41(17.0)$ & $5(2.1)$ \\
\hline Muslim & $2(0.8)$ & $3(1.3)$ & $37(15.4)$ \\
\hline Nazareth/Shembe & $15(6.2)$ & $22(9.2)$ & $7(2.9)$ \\
\hline Hindu & $5(2.1)$ & $2(0.8)$ & $22(9.1)$ \\
\hline Other & $12(5.0)$ & $10(4.1)$ & $\mathbf{2 4 1 ( 1 0 0 )}$ \\
\hline Total & $\mathbf{1 6 3 ( 6 7 . 6 )}$ & $\mathbf{7 8 ( 3 2 . 4 )}$ & \\
\hline
\end{tabular}

BTL: bilateral tubal ligation; * Percentage calculated on the denominator of $\mathrm{n}=241$

\section{Discussion}

The level of education, employment status and religious belief showed a statistically significant association with knowledge, attitudes, and perceptions of the study participants on postpartum BTL. It is therefore very important to explore and accommodate these factors whenever counselling on BTL is conducted, without compromising the quality and standard of counselling information. The area of residence did not show a statistical significant association with the knowledge, attitudes and perceptions of participants in the study, however, this could be associated with migration patterns of the population giving a diverse picture of participants' characteristics in those areas.

Sixty nine percent of the study participants preferred to have postpartum BTL after completing their family size. This is consistent with previous studies, which showed that tubal sterilization is one of the contraceptive methods of choice ${ }^{5}$. A significant number of participants below the age of 30 years believed that reversal of fertility is guaranteed post BTL. This is concerning because the risk of BTL regret can be as high as $20.3 \%$ for this age group $^{6,7}$. Regret can be verbalized by the patient, with or without signs of depression, patients requesting reversal of the procedure or requesting some assisted reproductive technique. Although the pregnancy rate following microsurgical reversal of BTL is $85.7 \%$ in women $\leq 35$ years of age, irrespective of the previous sterilization technique used ${ }^{8}$, this procedure is not always readily available in public hospitals of low income countries due to limited resources. A small number of participants aged $\geq 36$ years were not agreeable to BTL after completing their family size. This high risk group require ongoing family planning counselling in order to make informed decision.

The study found that $32.4 \%$ of participants compared to $16.67 \%$ in the literature regarded contraception as anti-religion ${ }^{5}$. Participants from the same religion gave different answers regarding BTL practices. This highlights the importance of a standardized, proper counselling on BTL irrespective of religious beliefs of the patient.

Our study found a higher $57.7 \%$ compared to $8.83 \%$ from the previous studies where spouses influenced the contraceptive method ${ }^{5}$. High unemployment rates in the sampled community may influence our findings. Although the involvement of the spouse/partner is recommended in family planning, patients must be aware that they can take a decision on their own. This is important in communities with poor spousal support in family planning. Patients must also be counselled about the fact that they can change their minds before the BTL procedure.

The finding of $27.8 \%$ of women who believed that BTL protects against STIs/ HIV was a concern. Women with tertiary education accounted for $2.5 \%$ of this finding. Patients need to be told that only consistent condom use or abstinence are capable of protecting against STIs and $\mathrm{HIV}^{2}$

Another concerning finding was that of $51.9 \%$ of women who did not know about the possibility of falling pregnant post BTL. This may result in delayed presentation 
to health care facilities and diagnosis of ectopic pregnancies. The CREST study showed that one third of post tubal sterilization pregnancies were ectopic ${ }^{9}$. Although previous studies showed either no change or improvement in sexual function, sexual desire, sexual satisfaction, coital frequency, and self-perceived femininity ${ }^{10}, 19 \%$ of participants believed that BTL will affect their sexual life negatively.

The strength of the study is that it was conducted in high risk participants who are more likely to benefit from BTL. The gaps identified directly highlight the unmet need of contraception awareness to pregnant women and indirectly to the community in general. The researchers are of the opinion that Greys Hospital serves a demographically diverse population. This gives health care givers of the area a general idea of the population's knowledge regarding tubal ligation. The demographic profile in the study population reflects that of the general population in the province.

The study has its' limitations. It was conducted in a single tertiary health centre which may introduce selection bias. Most questions required YES/NO answers which increased the possibility of guesswork. The aim was to eliminate "I don't know" answer so as to make a practical scenario where respondents would make a decision based on what they knew and what they thought.

\section{Conclusion}

The study highlights the extent of the challenge regarding BTL in this population and possibly in other populations with similar characteristics. The findings of the study can be used to improve our local tubal sterilization and contraception strategies. This can reduce the risk of post tubal ligation regret, delayed consultations for ectopic pregnancies, unprotected sex leading to STIs and possible litigation to the health care worker for poor counselling. Extending BTL counselling and contraception awareness beyond antenatal women to the population in general is recommended to close the gap of lack of knowledge and misperceptions. Different stakeholders of society must be involved to target all the influential demographic factors in order to improve awareness and change the mind set of the population.

\section{References}

1. Darroch JE, Singh S. Trends in contraceptive need and use in developing countries in 2003, 2008, and 2012: an analysis of national surveys. The Lancet. 2013;381(9879):1756-62.

2. World Health Organization. Improving access to quality care in family planning: Medical eligibility criteria for contraceptive use. $2 \mathrm{~d}$ ed. Geneva: Reproductive HealthAnd Research, World Health Organization, 2000. [http://www.who.int/iris/handle/10665/61086]

3. Peterson HB, Xia Z, Hughes JM, Wilcox LS, Tylor LR, Trussell J. The risk of pregnancy after tubal sterilization: findings from the U.S. Collaborative Review of Sterilization. Am J Obstet Gynecol. 1996; 174(4):1161-1170. 4. Pati S, Cullins V. Female sterilization. Evidence. Obstet Gynecol Clin North Am. 2000; 27(4):859-899.

5. Sajid A, Malik S. Knowledge, Attitude and Practice of Contraception Among Multiparous Women at Lady Aitchison Hospital, Lahore. Annals. 2010; 16(4): 266-269. 6. Hillis SD, Marchbanks PA, Tylor LR, Peterson HB. Post sterilization regret: findngs from the United States Collaborative Review of Sterilization. Obstet Gynecol. 1999;93(6);889-895.

7. Curtis KM, Mohllajee AP, Peterson HB. Regret following female sterilization at a young age: a systematic review. Contraception. 2006; 73:205-210

8. Hanafi M.M. Factors affecting the pregnancy rate after microsurgical reversal of tubal ligation: Fertility and sterility. 2003; 80(2):434-440.

9. Peterson HB, Xia Z, Hughes JM, Wilcox LS, Tylor LR, Trussell J. The risk of ectopic pregnancy after tubal sterilization. U.S. Collaborative Review of Sterilization Working Group. N EnglJ Med. 1997; 336(11):762-767.

10. Shain RN, Miller WB, Holden AE, Rosenthal M. Impact of tubal sterilization and vasectomy on female marital sexuality: Results of a controlled longitudinal study. Am J Obstet Gynecol. 1991;164(3):763-771. 